\title{
Axonal inclusions in spinocerebellar ataxia type 3
}

\author{
Kay Seidel • Wilfred F. A. den Dunnen • Christian Schultz • Henry Paulson • \\ Stefanie Frank - Rob A. de Vos • Ewout R. Brunt - Thomas Deller • \\ Harm H. Kampinga $\cdot$ Udo Rüb
}

Received: 28 January 2010/Revised: 29 June 2010/ Accepted: 2 July 2010/Published online: 16 July 2010

(C) The Author(s) 2010. This article is published with open access at Springerlink.com

\begin{abstract}
Protein aggregation is a major pathological hallmark of many neurodegenerative disorders including polyglutamine diseases. Aggregation of the mutated form of the disease protein ataxin-3 into neuronal nuclear inclusions is well described in the polyglutamine disorder spinocerebellar ataxia type 3 (SCA3 or Machado-Joseph disease), although these inclusions are not thought to be directly pathogenic. Neuropil aggregates have not yet been described in SCA3. We performed a systematic immunohistochemical study of serial thick sections through brains of seven clinically diagnosed and genetically confirmed SCA3 patients. Using antibodies against ataxin-3, p62, ubiquitin, the polyglutamine marker $1 \mathrm{C} 2$ as well as TDP-43, we analyzed neuronal localization, composition and distribution of aggregates within SCA3 brains. The analysis revealed widespread axonal aggregates in fiber tracts known to undergo neurodegeneration in SCA3. Similar to neuronal nuclear inclusions, the axonal aggregates were ubiquitinated and immunopositive for the proteasome and autophagy
\end{abstract}

K. Seidel $(\bowtie)$. W. F. A. den Dunnen

Department of Pathology and Medical Biology, University

Medical Centre Groningen, University of Groningen,

Hanzeplein 1, 9713 RB Groningen, The Netherlands

e-mail: Kay_Seidel@gmx.de

K. Seidel · C. Schultz · S. Frank · T. Deller · U. Rüb

Institute of Clinical Neuroanatomy, Dr. Senckenberg Anatomy,

J. W. Goethe University, Theodor-Stern-Kai 7,

60590 Frankfurt, Germany

H. Paulson

Department of Neurology, University of Michigan,

1500 E. Medical Centre Drive, MI4819 Ann Arbor, MI, USA

R. A. de Vos

Laboratorium Pathologie Oost Nederland, Burgemeester Edo

Bergsmalaan 1, 7512 AD Enschede, The Netherlands associated shuttle protein p62, indicating involvement of neuronal protein quality control mechanisms. Rare TDP-43 positive axonal inclusions were also observed. Based on the correlation between affected fiber tracts and degenerating neuronal nuclei, we hypothesize that these novel axonal inclusions may be detrimental to axonal transport mechanisms and thereby contribute to degeneration of nerve cells in SCA3.

Keywords Ataxin-3 - Axonal aggregates .

Polyglutamine diseases · Protein aggregates - SCA3

\section{Introduction}

Spinocerebellar ataxia type 3 (SCA3) is an autosomal dominantly inherited progressive neurodegenerative disease. It usually begins in adulthood and is associated with gait, stance, and limb ataxia, dysarthria, dysphagia,

\section{E. R. Brunt \\ Department of Neurology, University Medical Centre \\ Groningen, University of Groningen, Hanzeplein 1, \\ 9713 RB Groningen, The Netherlands}

\section{H. H. Kampinga}

Department of Cell Biology, University of Groningen,

Antonius Deusinglaan 1, 9713 AV Groningen, The Netherlands

C. Schultz

Section of Neuroanatomy, Center for Biomedicine and Medical

Technology Mannheim (CBTM), Medical Faculty Mannheim,

Ruprecht Karls-University Heidelberg, Ludolf-Krehl-Strasse

13-17, 68167 Mannheim, Germany 
oculomotor dysfunction, pyramidal and extrapyramidal signs, peripheral neuropathy, as well as aspiration pneumonia due to dysphagia [1, 9, 27, 33, 39].

Along with dentatorubral-pallidoluysian atrophy, Huntington's disease, spinobulbar muscular atrophy and the spinocerebellar ataxias types 1, 2, 6, 7 and 17, SCA3 belongs to the polyglutamine diseases [21, 25, 27, 40, 45]. These severe neurodegenerative diseases are caused by expanded and meiotically unstable CAG-repeat sequences at disease-specific gene loci encoding elongated polyglutamine sequences in the disease protein $[21,25,40]$. The SCA3 disease gene, ATXN3, codes for the disease protein ataxin-3 [20], contains 12-40 CAG-repeats in healthy individuals and approximately 53+ CAG-repeats in affected SCA3 patients and at-risk carriers [27]. Onset and severity of SCA3 correlates with the length of the expanded CAG-repeats [11].

Ataxin-3 is widely expressed in neuronal and non-neuronal tissue $[3,29,48]$ and tends to aggregate into neuronal nuclear inclusion bodies (NNIs) in vitro and in vivo when the polyglutamine sequence is expanded. It is well-known that these NNIs of the disease protein are ubiquitinated, contain other proteins, including heat shock proteins (HSPs) and transcription factors [18, 26, 29, 30, 38, 51], are frequently observed in brain tissue of SCA3 patients and are regarded as an important morphological hallmark of neurodegeneration in animal models [5]. However, the exact role of NNIs in neuronal cell death that occurs in SCA3 remains uncertain [24, 52]. Since, however, NNIs are present in degenerated as well as spared brain regions in advanced SCA3, NNIs are not thought to be directly pathogenic in affected nerve cells [35].

We here present the first systematical study on neuropil aggregates in SCA3 and describe their axonal localization, composition and brain distribution. The ataxin-3 immunopositive axonal inclusions newly described in the present study are immunopositive for ubiquitin and p62
(Sequestosome-1, SQSTM-1), but immunonegative for hyperphosphorylated tau and alpha-synuclein.

\section{Patients and methods}

Patients and control individuals

In the present investigation, we studied the brains of seven patients with clinically and genetically diagnosed SCA3 (5 males, 2 females, mean age at death $58.1 \pm 13.9$ years), along with the brains from two individuals without medical histories of neuropsychiatric diseases (Table 1). These two brains were employed as negative controls for the immunohistochemical analyses.

Informed consent was obtained from all patients, in accordance with the medical ethical committee of the University Medical Centre Groningen, the Netherlands, where the autopsies were performed. The ethical board of the Faculty of Medicine at the Johann Wolfgang Goethe University of Frankfurt/Main, Germany, also approved the examination of the brains.

All of the SCA3 patients suffered from gait, stance and limb ataxia, dysarthria, dysphagia and a variety of oculomotor dysfunctions. Genetical diagnosis was carried out in all SCA3 patients by genotyping the DNA extracted from peripheral lymphocytes with polymorphic dinucleotide repeat sequences that flank the specific ataxin-3 gene loci $[20,50]$. In the SCA3 patients studied, the length of the normal CAG-repeats varied from 14 to 27, while the pathologically expanded CAG-repeats varied from 62 to 81 (Table 1).

\section{Brain tissue preparation}

The brains of all SCA3 patients and control individuals were fixed in a $4 \%$ phosphate-buffered, aqueous formaldehyde
Table 1 Information on SCA3 patients and healthy controls

Patient number, age of death (years), gender ( $F$ female, $M$ male), number of CAGrepeats in the healthy/diseased SCA3 allele, age at onset of initial disease symptoms (years) and duration of disease (years) (ND not determined)

\begin{tabular}{ccllll}
\hline Case & $\begin{array}{l}\text { Age at death } \\
\text { (years) }\end{array}$ & Gender & $\begin{array}{l}\text { CAG-repeat } \\
\text { length }\end{array}$ & $\begin{array}{l}\text { Age at disease } \\
\text { onset (years) }\end{array}$ & $\begin{array}{l}\text { Disease duration } \\
\text { (years) }\end{array}$ \\
\hline \multicolumn{2}{l}{ SCA3 patients } & & & & \\
1 & 24 & M & $23 / 81$ & 13 & 11 \\
2 & 45 & M & $21 / 69$ & 25 & 20 \\
3 & 52 & M & $14 / 69$ & 30 & 22 \\
4 & 56 & M & $25 / 74$ & 30 & 26 \\
5 & 62 & F & $20 / 73$ & 35 & 25 \\
6 & 80 & F & $27 / 65$ & 55 & 26 \\
7 & 85 & M & $21 / 62$ & 59 & - \\
Control cases & & & & & - \\
8 & 87 & M & ND & - & - \\
9 & 74 & F & ND & - & \\
\hline
\end{tabular}


Table 2 Information on the primary antibodies

\begin{tabular}{|c|c|c|c|c|c|}
\hline Detection & Clone & Host species & Dilution & Source & Goal \\
\hline Ataxin-3 & - & Rabbit polyclonal & $1: 750$ & Henry Paulson laboratory & Aggregate marker \\
\hline Ataxin-3, epitope E214-L233 & $1 \mathrm{H} 9$ & Mouse monoclonal & $1: 2,500$ & $\begin{array}{r}\text { Chemicon (Millipore), } \\
\text { Billerica, MA, USA }\end{array}$ & Aggregate marker \\
\hline Ubiquitin & $\mathrm{p} 4 \mathrm{~d} 1$ & Mouse monoclonal & $1: 750$ & $\begin{array}{l}\text { Cell Signaling Technology, } \\
\text { Danvers, MA, USA }\end{array}$ & $\begin{array}{l}\text { Aggregate marker/marker } \\
\text { for proteasomal activity }\end{array}$ \\
\hline P62 & Sc-25575 & Rabbit polyclonal & $1: 100$ & $\begin{array}{l}\text { Santa Cruz, Delaware, CA, } \\
\text { USA }\end{array}$ & $\begin{array}{l}\text { Aggregate marker/marker } \\
\text { for proteasomal activity }\end{array}$ \\
\hline Polyglutamine stretch & $1 \mathrm{C} 2$ & Mouse monoclonal & $1: 2,000$ & $\begin{array}{r}\text { Chemicon (Millipore), } \\
\text { Billerica, MA, USA }\end{array}$ & Aggregate marker \\
\hline Alpha-synuclein & - & Sheep polyclonal & $1: 2,000$ & W.P Gai laboratory & Aggregate marker \\
\hline Hyperphosphorylated tau & AT8 & Mouse monoclonal & $1: 2,000$ & Innogenics, Ghent, Belgium & Aggregate marker \\
\hline Microtubule-associated protein tau & AT270 & Mouse monoclonal & $1: 3,000$ & $\begin{array}{l}\text { Pierce Endogen, Rockford, } \\
\text { IL, USA }\end{array}$ & Axonal marker \\
\hline Neurofilament & ab 30309 & Rabbit polyclonal & $1: 100$ & Abcam, Cambridge, UK & Axonal marker \\
\hline Tryptophan hydroxylase & PH8 & Mouse monoclonal & $1: 1,000$ & $\begin{array}{r}\text { Chemicon (Millipore), } \\
\text { Billerica, MA, USA }\end{array}$ & $\begin{array}{l}\text { Marker for serotonergic } \\
\text { cells }\end{array}$ \\
\hline Tyrosine hydroxylase & MAB152 & Rabbit polyclonal & $1: 2,000$ & $\begin{array}{r}\text { Chemicon (Millipore), } \\
\text { Billerica, MA, USA }\end{array}$ & $\begin{array}{l}\text { Marker for dopaminergic } \\
\text { and noradrenergic cells }\end{array}$ \\
\hline TDP-43 & - & Rabbit polyclonal & $1: 1,000$ & Georg Auburger laboratory & Aggregate marker \\
\hline
\end{tabular}

Antigen detected by antibody, clone or catalog designation (omitted with donated antibodies), host species and clone type, working dilution for the antibody, source of the antibody, specific goal of the antibody usage

solution (pH 7.4). Thereafter, tissue blocks from the left cerebral hemispheres and brainstems were embedded in polyethylene glycol (PEG 1000, Merck, Darmstadt, Germany) [44] and cut into sets of uninterrupted series of $100 \mu$ m-thick frontal sections (cerebral tissue blocks) or $100 \mu \mathrm{m}$-thick horizontal sections (brainstem tissue blocks) $[8,32]$. Brainstem tissue blocks from case 7 were also embedded in paraffin and cut into $10 \mu \mathrm{m}$ thick horizontal sections.

In each instance, one set of cerebral and brainstem serial sections was stained with Darrow red for Nissl material and aldehyde-fuchsin for lipofuscin pigment and used for topographical orientation and assessment of neurodegeneration [8].

\section{Immunohistochemistry}

For the identification and subcellular localization of neuropil aggregates, we employed the anti-ataxin-3 antibody [29] on select $100 \mu \mathrm{m}$ cerebral and brainstem sections (see Table 2 for a list of the primary antibodies). The primary incubation lasted $20 \mathrm{~h}$ at room temperature. This was followed by incubation with a secondary, biotin conjugated antibody for $90 \mathrm{~min}$ at room temperature (1:300). Subsequently, we used the ABC complex (Vectastain, Vector Laboratories, Burlingame, CA, USA) and 3,3-diaminobenzidine-tetra- $\mathrm{HCl} / \mathrm{H}_{2} \mathrm{O}_{2}$ (DAB, D5637 Sigma, Taufkirchen, Germany) to visualize positive immunoreactions, resulting in a brown staining.
Double immunostaining procedures were employed to examine the intraaxonal localization, topographical distribution and composition of neuropil aggregates. Axonal markers (i.e. the AT270 antibody, directed against the cytoskeletal protein tau; the anti-neurofilament antibody, directed against neuron specific intermediate filaments [15, 43]) were used to ascertain axonal localization of neuropil aggregates. Additional monoclonal antibodies were applied as whole cell markers to identify protein aggregates within neurites of serotonergic (i.e. PH8, directed against tryptophan hydroxylase), as well as dopaminergic or noradrenergic neurons (i.e. MAB 152, directed against tyrosine hydroxylase) $[4,17]$.

In addition to the polyclonal rabbit anti-ataxin-3 antibody, we employed the monoclonal $1 \mathrm{H} 9$ anti-ataxin-3 [48], TDP43 [47] as well as the $1 \mathrm{C} 2$ polyglutamine antibodies as aggregate markers [49]. The possible association of the axonal aggregates of SCA3 with the proteasomal shuttle protein p62, known to contribute to aggregations in human neurodegenerative diseases, was investigated with an antibody directed against p62 [7, 12, 22, 23, 41, 42]. Axonal and whole cell stainings were visualized with SK4700, aggregation markers and the anti-p62 antibody with DAB.

For double immunostaining, we followed the single staining procedure as described above. After the DAB staining reaction, the slides were rinsed carefully and incubated with an additional primary antibody (axonal or whole cell marker) for $20 \mathrm{~h}$ at room temperature, followed 
by incubation with a secondary antibody at room temperature for $90 \mathrm{~min}$. This second staining reaction was then visualized with the SK 4700 Kit (Linaris, 97877 Wertheim, Germany), resulting in a blue-gray staining.

Double immunofluorescent staining was applied to ascertain $1 \mathrm{C} 2$ and TDP-43 positivity of axonal aggregates, and to investigate the colocalization of ataxin-3 aggregates with components of the protein quality control and degradation pathways, or with the disease proteins of human tauopathies and synucleinopathies. For this, sections were treated for $10 \mathrm{~min}$ with $0.06 \%$ sudan-black for quenching of autofluorescence. Subsequently, the sections were incubated with both the monoclonal mouse and polyclonal rabbit primary antibodies for $20 \mathrm{~h}$ at room temperature, followed by secondary incubation for 90 min with Alexa 488, Alexa 568 or Alexa 594 conjugated secondary antibodies (1:1,000, Invitrogen, Carlsbad, CA, USA). Both the primary and the secondary antibodies were applied simultaneously. We used the $1 \mathrm{C} 2$ antibody to confirm the presence of proteins with an expanded polyglutamine sequence in the axonal aggregates [49]. Ubiquitin [10] and p62 antibodies were employed to investigate a possible colocalization of axonal ataxin-3 aggregates with components of the protein quality control and degradation pathways. The anti-tau AT8 antibody and an anti-alphasynuclein antibody $[6,14]$ were used to examine the association of axonal ataxin-3 aggregates with the hyperphosphorylated tau or alpha-synuclein proteins.

Several of the listed antibodies required pre-treatment for antigen retrieval. To unmask hidden epitopes when using the $1 \mathrm{H} 9$ antibody, sections were autoclaved in $10 \mathrm{mM}$ citrate buffer (pH 6.0) for $20 \mathrm{~min}$. For the antineurofilament and anti-p62 antibodies we employed $10 \mathrm{mM}$ citrate buffer $\left(\mathrm{pH} \mathrm{6.0)}\right.$ at $90^{\circ} \mathrm{C}$ for $30 \mathrm{~min}$. For the anti-alpha-synuclein antibody we used $100 \%$ formic acid at room temperature. For the 1C2/neurofilament double immunostaining we employed $3 \times 10 \mathrm{~min}$ microwaving in tris Buffer ( $\mathrm{pH}$ 9.0), followed by 3 min treatment in $99 \%$ formic acid at room temperature. The specificity of the immunolabeling was verified by omission of the primary antibodies which resulted in complete absence of immunopositive structures.

\section{Evaluation of the distribution of axonal aggregates}

The severity of the axonal ataxin-3 pathology was assessed in select tissue sections. If a given tract bore an axonal inclusion at least once in all sections investigated in one patient, the fiber tract's axonal pathology was scored as mild for this patient (score: 1). If it contained single aggregates in the majority of the investigated sections or 3 or more aggregates in a single section of a given patient, axonal pathology was rated as moderate (score: 2). If a tract displayed 3 or more aggregates in more than half of all sections of one patient, axonal pathology was rated as severe (score: 3 ).

\section{Statistics}

SPSS version 16.0 was used for statistical analysis. Bivariate correlations between patient data and morphological findings were evaluated using Spearman's Rho. Two-tailed tests were performed and considered significant at $p<0.05$.

\section{Results}

In contrast to the control individuals, the combined application of the tau-antibody AT270 [15], as axonal marker, and the rabbit anti-ataxin-3 antibody [29], as a marker of ataxin-3 protein aggregation, revealed intensively labeled intra-axonal inclusion bodies in all seven SCA3 patients (Fig. 1; Table 3).

Except for the external and extreme capsules and the hippocampal alveus, all of the evaluated brain fiber tracts were at least mildly affected by these axonal inclusions (Table 3). Among the most severely affected fiber tracts were the medial longitudinal fascicle, and the rubrospinal and nigrostriatal tracts. Additional consistently affected fiber tracts included the cranial nerves (oculomotor, trigeminal, facial, vagal and hypoglossal nerves), the cuneate and gracile fascicles, the lateral lemniscus, the central tegmental tract, the internal arcuate fibers, the dorsal spinocerebellar tract, the lenticular ansa and the inferior thalamic peduncle (Figs. 1, 2, 3, 4, 5, 6; Table 3).

Most axonal aggregates were irregular in shape (Fig. 1e, g), some were ovoid (Fig. 1a-d), or elongated and displayed a neuritic-like shape (Fig. 1f, h). The size of axonal aggregates varied from approximately the diameter of the corresponding axon (Fig. 1b) to a size substantially larger than the normal axonal diameter (Fig. 1c, d, g). These larger aggregates were often accompanied by a comparative thickening of the corresponding axon (Fig. 1c, g). Sometimes thinning of the tau staining within the affected axon, proximal to the aggregations was visible, which indicates a dilation of the axonal structure (Fig. 1c). Ataxin-3 immunopositive axonal aggregates could be observed in all portions of the affected axons (i.e. axon hillock, proximal, middle and distal portions of the axon) (Fig. 2b). Several of the affected axons displayed numerous abnormal aggregates (Figs. 1d, f, 2a, d). Double immunostainings with the 1H9 or anti-p62 antibodies as aggregate markers and the anti-neurofilament or AT270 antibodies as an axonal markers yielded identical staining results (Fig. 3a-d). A few TDP-43 positive axonal inclusions were also observed (data not shown). 


\section{Fig. 1 Double}

immunostainings with antiataxin- 3 and the axonal marker AT270 showing axonal aggregates (arrows) in the pyramidal tract (a), oculomotor nerve (b), facial nerve (c, d), hypoglossal nerve (e-g) and nigrostriatal tract (h) of representative SCA3 patients. Axonal aggregates can vary in regards to morphology between ovoid (a-d), elongated (h) or irregular $(\mathbf{e}, \mathbf{g})$. Size is also variable, from small (e) to several times the axonal diameter $(\mathbf{c}, \mathbf{d}, \mathbf{g})$. Note the pallor of the tau staining, indicating axonal dilation (arrowhead) (c), and the comparatively large axonal diameter compared to the unaffected neighboring axons (arrowheads) (g). Eccentric placement of inclusions in the axon is rarely observable (arrow) (e). (a-h Anti-ataxin-3 immunostaining with $\mathrm{DAB}$ brown, AT270 stain with SK4700-blue-gray, $100 \mu \mathrm{m}$ PEG sections)
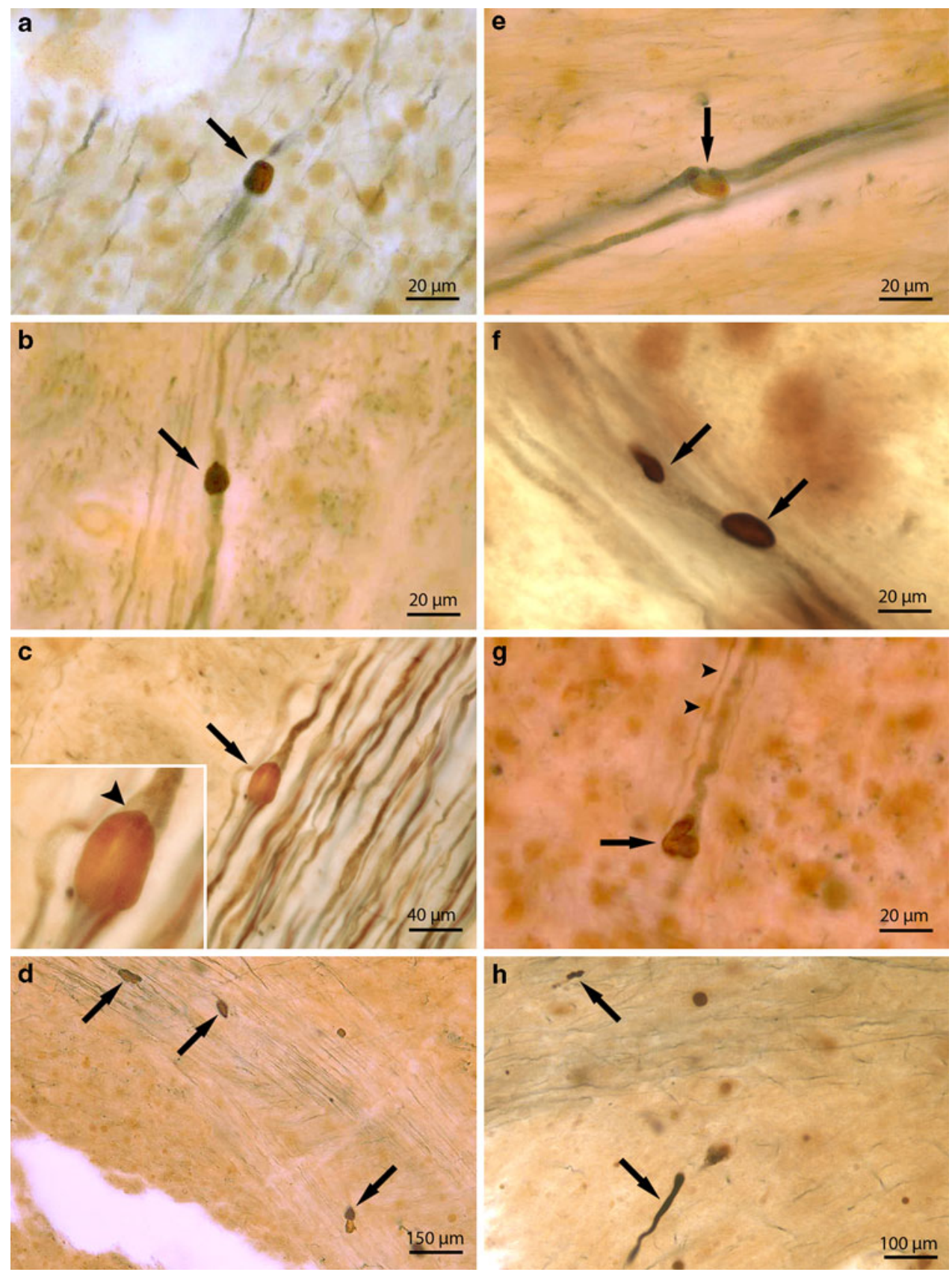

Combined immunostaining with anti-ataxin-3 antibody and anti-tryptophan hydroxylase PH8 [17] or anti-tyrosine hydroxylase [4] antibodies demonstrated the axonal localization of ataxin-3 immunopositive aggregates in nerve cells of the serotonergic raphe nuclei (Fig. 2a, b), in dopaminergic nigral neurons (Fig. 2c), and in noradrenergic nerve cells of the locus coeruleus (Fig. 2d). Additional double immunostainings confirmed the presence of expanded polyglutamine stretches in the axonal protein aggregates (Fig. 4), demonstrated their ubiquitination [10] (Fig. 5) and immunopositivity for the shuttle protein p62
[22] (Figs. 3a, b, 6a-f). These staining results were highly similar to those with the anti-ataxin-3/AT270 double staining. Finally, the axonal inclusions in all of the SCA3 patients were immunonegative for abnormal tau and alphasynuclein protein aggregations (data not shown), and did not demonstrate significant accumulations of neurofilament (Fig. 4).

Statistical analysis revealed a significant negative correlation between the axonal scores of the SCA3 patients and the length of the CAG-repeat in the mutated SCA3 gene (Spearman's Rho $-0.793, p=0.033$ ). 
Table 3 Distribution and severity of axonal pathology in SCA3 patients
Investigated brain fiber tract, rating of axonal ataxin-3 pathology sorted by increasing severity (none: 0 ; slight: $1-5$; marked: 6-10; severe: $11+$ ) indicated by different shades of gray ( $N D$ not determined)

\begin{tabular}{|c|c|c|c|c|c|c|c|c|}
\hline Fiber tract & 1 & 2 & 3 & 4 & 5 & 6 & 7 & $\begin{array}{l}\text { Axonal } \\
\text { scores }\end{array}$ \\
\hline External capsule & 0 & 0 & 0 & 0 & 0 & 0 & 0 & 0 \\
\hline Extreme capsule & 0 & 0 & 0 & 0 & 0 & 0 & 0 & 0 \\
\hline Alveus of hippocampus & 0 & 0 & 0 & 0 & 0 & 0 & 0 & 0 \\
\hline Posterior commissure & 0 & 0 & 0 & 0 & 0 & 1 & 0 & 1 \\
\hline Optic radiation & 0 & 0 & 1 & 0 & 0 & 0 & 0 & 1 \\
\hline Acoustic radiation & 0 & 0 & 1 & 0 & 0 & 0 & 0 & 1 \\
\hline Corpus callosum & 0 & 0 & 1 & 0 & 0 & 1 & 0 & 2 \\
\hline Mamillothalamic tract & 0 & 0 & 0 & 0 & 0 & 1 & 1 & 2 \\
\hline Optic tract & 1 & 0 & 1 & 0 & 0 & 0 & 0 & 2 \\
\hline Posterior thalamic peduncle & 0 & 1 & 1 & 0 & 0 & 0 & 0 & 2 \\
\hline Abducens nerve & 0 & 0 & 1 & 0 & 0 & 1 & 0 & 2 \\
\hline Anterior thalamic peduncle & 0 & 1 & 0 & 0 & 1 & 0 & 1 & 3 \\
\hline Lateral thalamic peduncle & 0 & 1 & 1 & 0 & 0 & 1 & 0 & 3 \\
\hline Trochlear nerve & 0 & 2 & 1 & 0 & 0 & 0 & 1 & 4 \\
\hline Fornix & 0 & 0 & 1 & 1 & 1 & 0 & 1 & 4 \\
\hline Lateral vestibulospinal tract & 1 & 0 & 1 & 0 & 0 & 1 & 1 & 4 \\
\hline Inferior cerebellar peduncle & 0 & 0 & 1 & 0 & 1 & 1 & 1 & 4 \\
\hline Medial cerebellar peduncle & 1 & 0 & 1 & 1 & 0 & 1 & 1 & 5 \\
\hline Internal capsule & 0 & 0 & 2 & 1 & 1 & 0 & 1 & 5 \\
\hline Pontocerebellar fibers & 1 & 0 & 1 & 1 & 0 & 1 & 1 & 5 \\
\hline Medial vestibulospinal tract & 1 & 1 & 1 & 0 & 0 & 1 & 1 & 5 \\
\hline Trapezoid body & 1 & 1 & 1 & 1 & 1 & n.d. & 0 & 5 \\
\hline Acoustic striae & 1 & 1 & 1 & 1 & 0 & 1 & 0 & 5 \\
\hline Anterior commissure & 0 & 1 & 1 & 1 & 0 & 1 & 1 & 5 \\
\hline Ventral spinocerebellar tract & 1 & 0 & 1 & 1 & 1 & 1 & 1 & 6 \\
\hline Superior cerebellar peduncle & 0 & 1 & 1 & 1 & 1 & 1 & 1 & 6 \\
\hline Solitary tract & 1 & 0 & 1 & 1 & 1 & 1 & 1 & 6 \\
\hline Corticospinal tract & 0 & 1 & 1 & 1 & 1 & 1 & 1 & 6 \\
\hline Cerebral peduncle & 1 & 0 & 1 & 2 & 1 & 2 & 0 & 7 \\
\hline Medial lemniscus & 0 & 1 & 1 & 1 & 1 & 2 & 1 & 7 \\
\hline Ascending tract of Deiters & 1 & 2 & 1 & 1 & 1 & 0 & 1 & 7 \\
\hline Vestibulocochlear nerve & 0 & 1 & 1 & 2 & 1 & 1 & 1 & 7 \\
\hline Olivocerebellar fibers & 1 & 2 & 1 & 1 & 0 & 1 & 1 & 7 \\
\hline Dorsal spinocerebellar tract & 1 & 1 & 1 & 2 & 1 & 1 & 1 & 8 \\
\hline Inferior thalamic peduncle & 0 & 2 & 2 & 0 & 1 & 2 & 1 & 8 \\
\hline Oculomotor nerve & 1 & 0 & 2 & 1 & 0 & 2 & 2 & 8 \\
\hline Internal arcuate fibers & 0 & 1 & 1 & 1 & 2 & 2 & 2 & 9 \\
\hline Lenticular ansa & 1 & 1 & 2 & 2 & 1 & 1 & 2 & 10 \\
\hline Cuneate fascicle & 1 & 1 & 1 & 2 & 2 & 1 & 2 & 10 \\
\hline Central tegmental tract & 1 & 2 & 2 & 2 & 1 & 1 & 1 & 10 \\
\hline Hypoglossal nerve & 0 & 0 & 2 & 3 & 1 & 1 & 3 & 10 \\
\hline Lateral lemniscus & 1 & 1 & 1 & 2 & 1 & 2 & 2 & 10 \\
\hline Vagal nerve & 0 & 0 & 3 & 1 & 1 & 3 & 2 & 10 \\
\hline Trigeminal nerve & 1 & 1 & 2 & 2 & 1 & 1 & 3 & 11 \\
\hline Facial nerve & 1 & 1 & 3 & 1 & 1 & 3 & 1 & 11 \\
\hline Gracile fascicle & 1 & 2 & 1 & 2 & 2 & 1 & 2 & 11 \\
\hline Rubrospinal tract & 2 & 2 & 2 & 1 & 2 & 1 & 2 & 12 \\
\hline Nigrostriatal tract & 2 & 3 & 2 & 2 & 1 & 2 & 1 & 13 \\
\hline Medial longitudinal fascicle & 2 & 2 & 2 & 3 & 2 & 1 & 2 & 14 \\
\hline Axonal scores & 27 & 37 & 57 & 45 & 33 & 47 & 48 & \\
\hline
\end{tabular}

\section{Discussion}

Aggregation of the mutant disease protein is well known in polyglutamine diseases [21, 26, 40, 45]. In SCA3, mutant ataxin-3 tends to aggregate into NNIs with many affected neurons exhibiting more than one inclusion body, both in and outside of areas affected with neurodegeneration [29, 33, 35, 38]. While the exact role of these aggregates in the pathological mechanisms of SCA3 is still subject to research, they represent an acknowledged pathological hallmark of this disease. NNIs can be recognized by both ataxin- 3 specific antibodies as well as the anti-polyglutamine 1C2 antibody, implicating mutant ataxin-3 as the main component of NNI [49]. Furthermore, a variety of additional proteins are found to be associated with NNI (e.g. ubiquitin, p62, heat shock proteins, transcription factors) [18, 26, 29, 30, 38, 51]. Since polyubiquitination is a known prerequisite for proteasomal degradation and the shuttle protein p62 plays a crucial role in cellular pathways handling aberrant protein aggregation (e.g. ubiquitin-proteasome pathway, autophagy), the immunostaining of aggregates with antibodies against ubiquitin and p62 most likely reflects attempts by affected neurons to target the misfolded ataxin-3 into the 

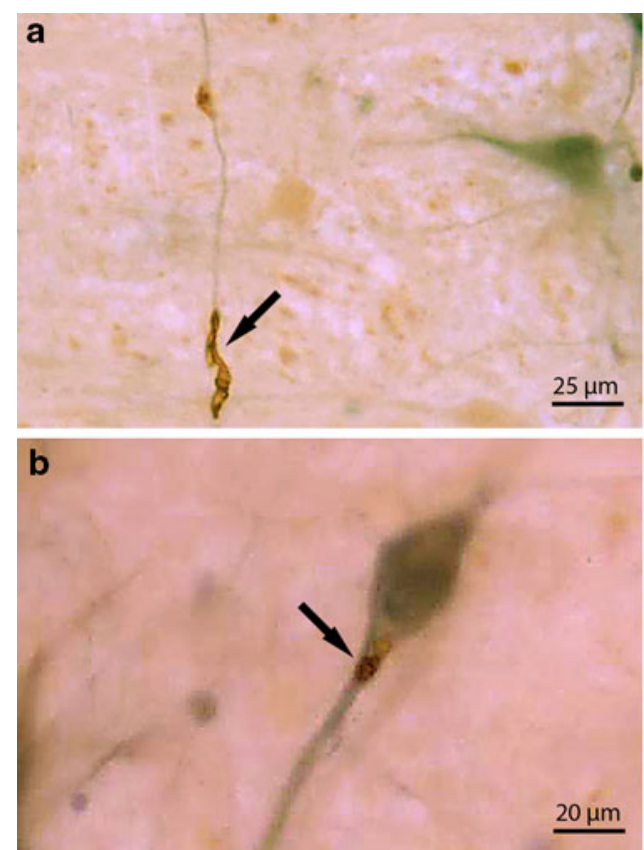

Fig. 2 Combined immunostainings with anti-ataxin-3 and anti-tryptophan hydroxylase or anti-tyrosine hydroxylase antibodies depicting axonal aggregates (arrows) in serotonergic nerve cells of the caudal raphe nuclei $(\mathbf{a}, \mathbf{b})$, dopaminergic nerve cells of the substantia nigra (c) and noradrenergic nerve cells of the locus coeruleus of a typical SCA3 patient (d). Note the ataxin-3 immunopositive aggregate in the
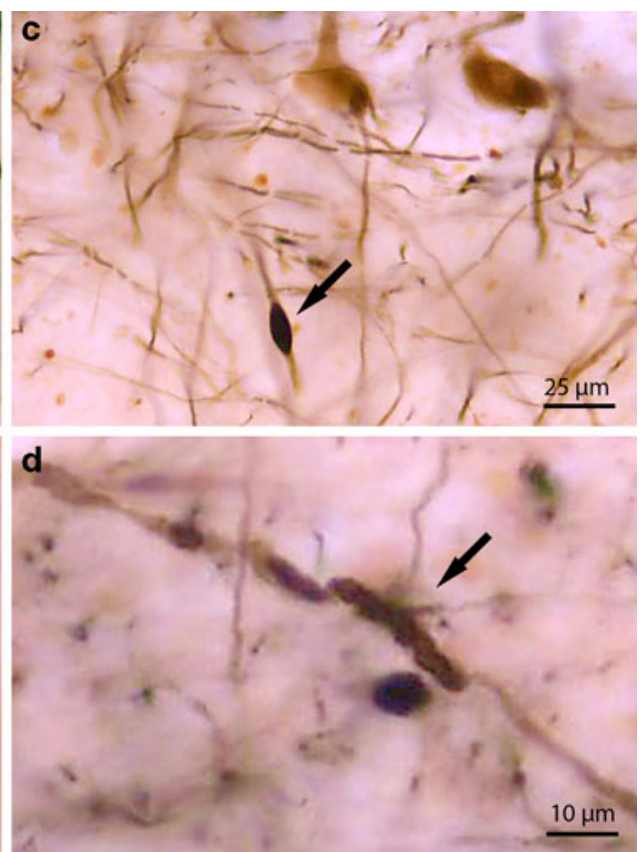

axonal hillock of a neuron of the caudal raphe nuclei (arrow) (b). (a, b Anti-ataxin-3 immunostaining with DAB-brown, PH8 immunostaining with SK4700-blue-gray, c, d Anti-ataxin-3 immunostaining with DAB - brown, anti-TH immunostaining with SK4700-bluegray, $100 \mu \mathrm{m}$ PEG sections)
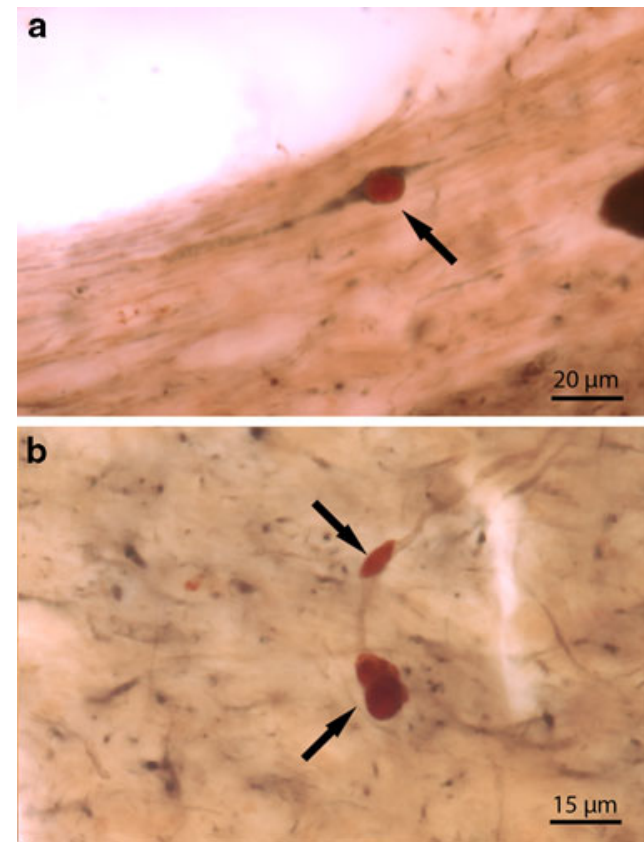

Fig. 3 Combined immunostaining with a p62 antibody and AT270 as axonal marker, as well as double immunostaining for anti-ataxin-3 and neurofilament as axonal marker. p62 immunopositive axonal aggregates (arrows) in the hypoglossal nerve (a) and in neurites within the substantia nigra of a representative SCA3 patient (b). Ataxin-3 immunopositive axonal aggregates (arrows) in the hypoglossal nerve
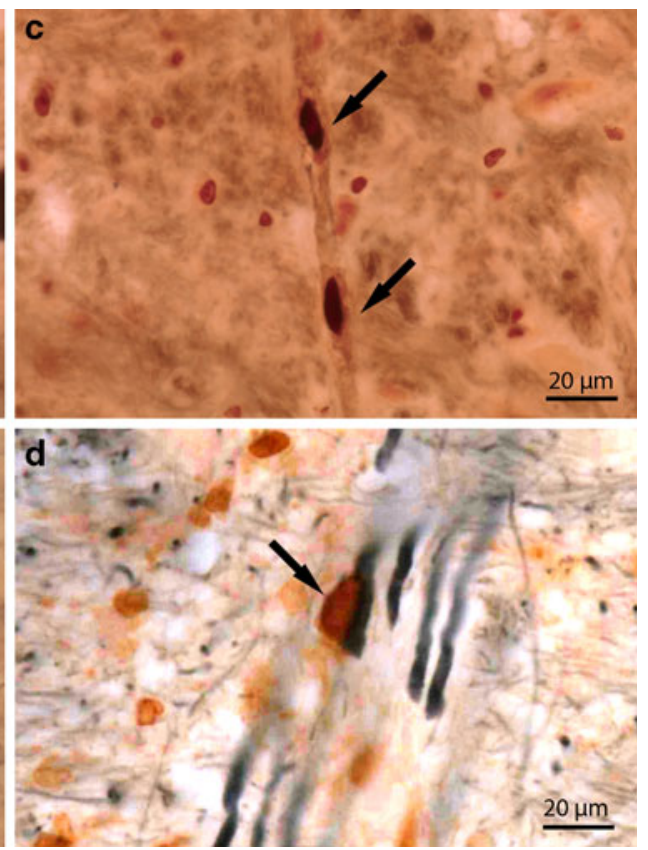

of a typical SCA3 patient (c, d). (a, b Anti-p62 immunostaining staining with DAB—brown, AT270 staining with SK 4700-blue-gray, c, $\mathbf{d} 1 \mathrm{H} 9$ anti-ataxin-3 immunostaining with DAB-brown, anti-neurofilament immunostaining with SK 4700—blue-gray, $100 \mu \mathrm{m}$ PEG sections) 
Fig. $41 C 2$ and antineurofilament double immunofluorescence. The oculomotor nerve $(\mathbf{a}, \mathbf{d})$ of a representative SCA3 patient shows 1C2 immunopositive aggregates indicating that ataxin-3 with an expanded polyglutamine stretch is a component of these aggregates $(\mathbf{b}, \mathbf{c}, \mathbf{e}, \mathbf{f})$. The low staining intensity of neurofilament indicates that these aggregates occur independently of age related neurofilament aggregation (a, d). (a-f Antineurofilament immunostaining with alexa 488-green, 1C2 immonostaining with Alexa 594-red, $10 \mu \mathrm{m}$ paraffin sections)
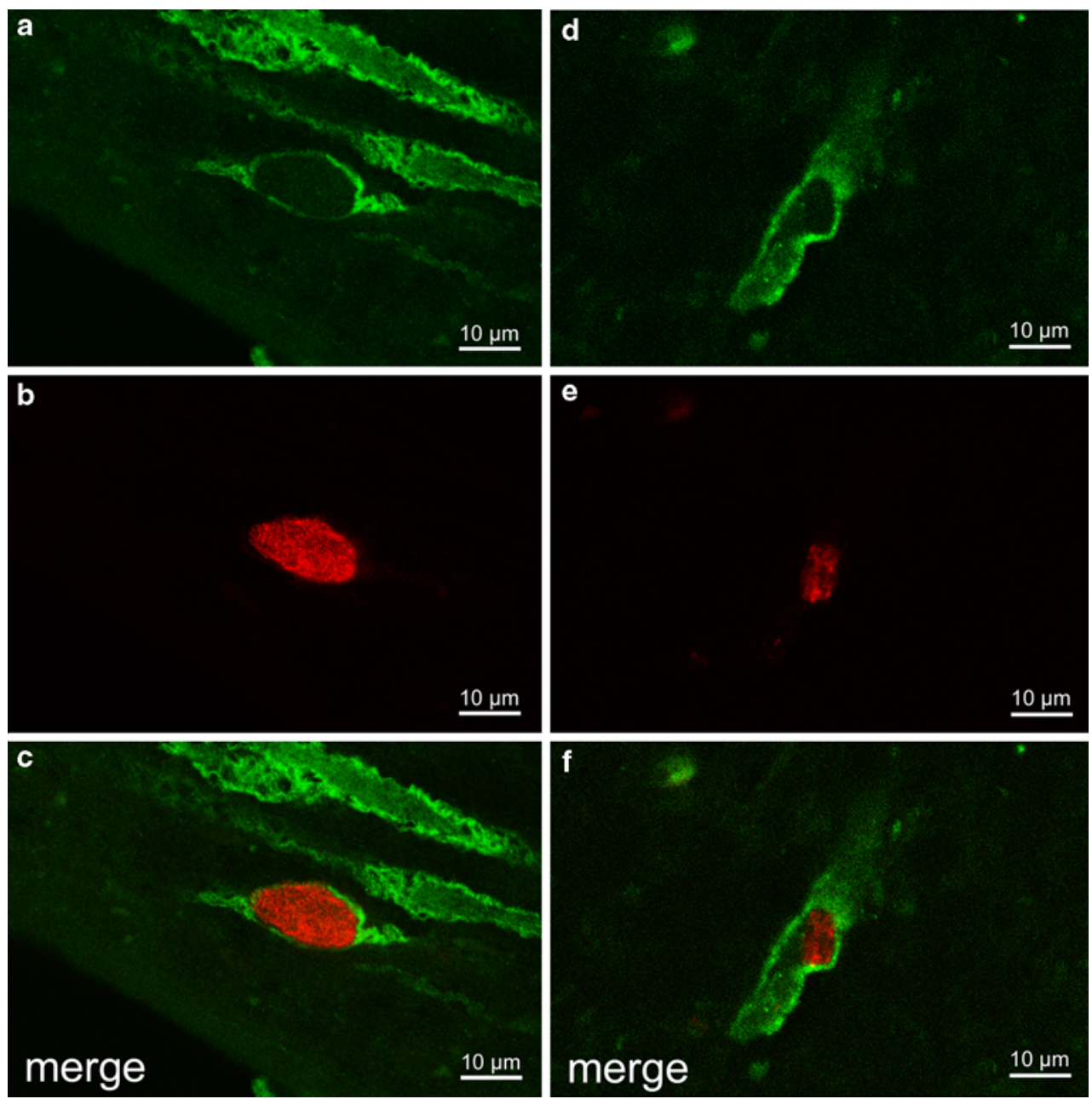

aforementioned protein degradation pathways $[2,7,10$, 22, 29, 41, 42].

Although many reports have provided detailed analyses of the distribution pattern of NNIs in SCA3 brains, the occurrence of axonal aggregates in SCA3 has remained unreported [28, 29, 35, 38]. We were for the first time able to demonstrate intra-axonal aggregations of mutant ataxin3 protein in SCA3 brain tissue, reminiscent of the neuritic aggregates in Huntington's disease [13]. These novel findings suggest that axonal aggregates represent consistent associated tissue changes of SCA3 present in a large number of brain fiber tracts. SCA3 thus becomes the first spinocerebellar ataxia to be associated with axonal aggregates.

The axonal inclusions detected in the present SCA3 study do not colocalize with and occur independently from neuronal aggregates of other human proteinopathies (e.g. tauopathies, synucleinopathies) and share major biological hallmarks with the long-known NNIs. They can be visualized with antibodies directed against ataxin-3, as well as with the $1 \mathrm{C} 2$ polyglutamine antibody, indicating that mutant ataxin-3 with its extended polyglutamine stretch likewise represents a primary component of these axonal aggregates [49]. Ataxin-3/ubiquitin or ataxin-3/p62 double immunoreactions confirmed their similar state of ubiquitination and association with the shuttle protein p62 as has been observed in NNIs, indicating comparable attempts by affected nerve cells to combat intra-axonal aggregation [2, $7,10,41]$. Only a few axonal inclusions were also TDP-43 immunopositive, indicating that TDP-43 immunopositivity is restricted only to a subset of axonal inclusions. Demonstration of the intra-axonal localization of these axonal aggregates is facilitated by the application of axonal markers (i.e. AT270 and anti-neurofilament antibodies) $[15,43]$, as well as whole cell markers for serotonergic, dopaminergic and noradrenergic nerve cells (i.e. PH8 and anti-TH antibodies) [4, 17].

Axonal inclusions were present in a large variety of fiber tracts of the SCA3 brains studied, irrespective of the caliber or length of the affected axons. They occurred predominantly in the fiber tracts that belong to the functional and neurotransmitter systems known to undergo neurodegeneration in the progressive neuropathology of SCA3 [9, 19, 31-37]. The affected fiber tracts serve as 
Fig. 5 Anti-ataxin-3 and antiubiquitin double

immunofluorescence. Ataxin-3 immunopositive axonal aggregate in the

vestibulocochlear nerve of a representative SCA3 patient $(\mathbf{a}-\mathbf{c})$. The colocalization of ubiquitin (red) and ataxin-3 (green) indicates polyubiquitination of this axonal aggregate $(\mathbf{a}-\mathbf{c})$. Reversed staining pattern of axonal aggregates in the nigrostriatal tract of an additional SCA3 patient $(\mathbf{d}-\mathbf{f})$. These aggregates, likewise, show colocalization of ubiquitin (green) and ataxin-3 (red) (d-f) (a-c Anti-ataxin-3

immunostaining with Alexa 488-green, Anti-ubiquitin stain with Alexa 568-red, df anti-ataxin-3 immunostaining with Alexa 568-red, Antiubiquitin stain with Alexa 488-green, $100 \mu \mathrm{m}$ PEG sections)
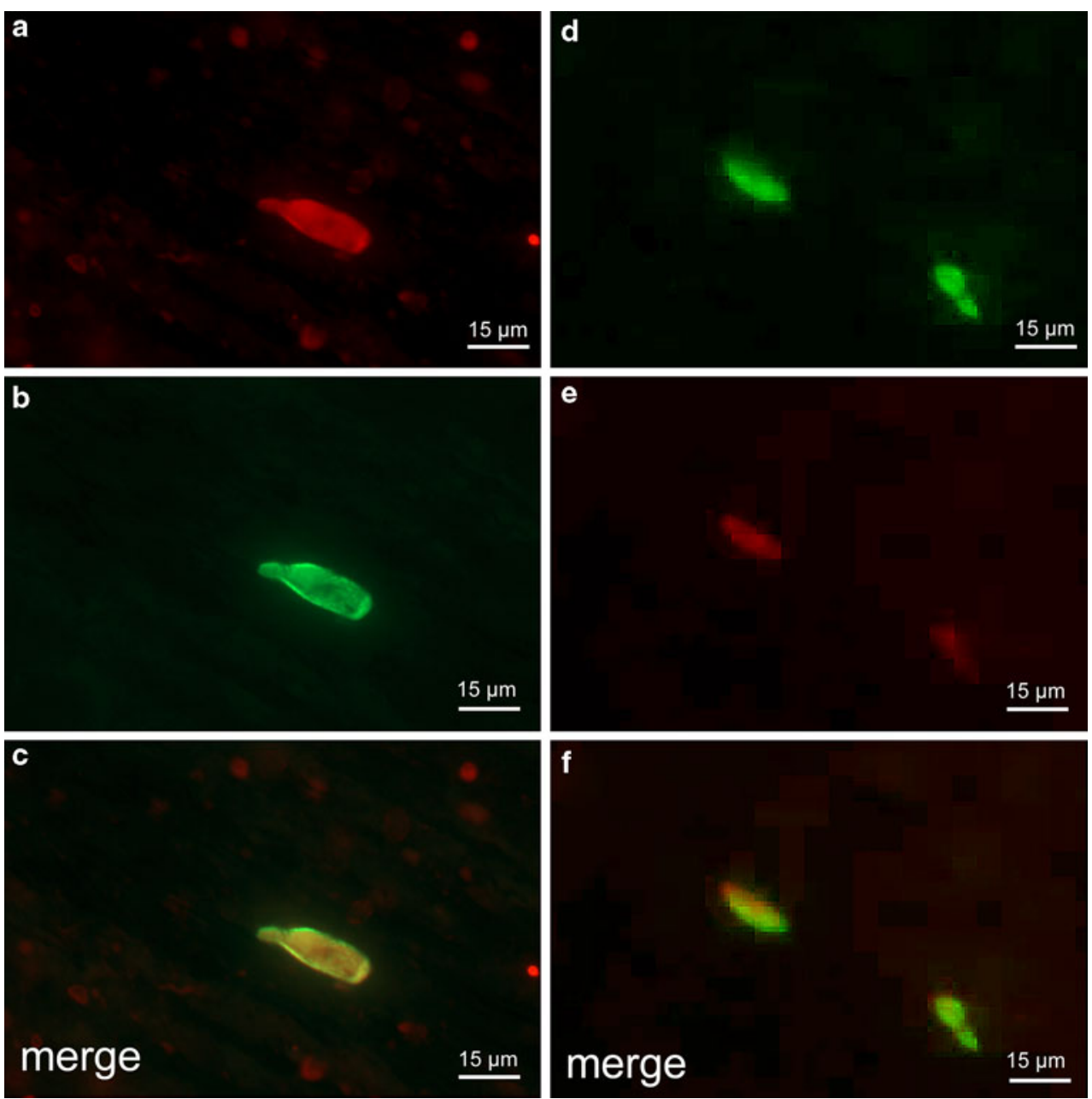

anatomical interconnections between gray components, which have been shown to be selectively, consistently and severely affected by neurodegeneration (e.g. cerebellar dentate nucleus, primary motor cortex, sensory and motor thalamic nuclei, substantia nigra, precerebellar nuclei, ingestion-related brainstem nuclei, vestibular nuclei, auditory and oculomotor nuclei, somatosensory nuclei) in patients in the advanced clinical stages of SCA3, including several of the patients investigated in the present study [19, 31-37]. In view of the close correlation of the occurrence of intra-axonal aggregates with the consistent demise of nerve cells in the afferent sources and/or efferent targets of these affected fiber tracts it is conceivable that the formation of axonal aggregates, irrespective of their primarily toxic or protective role, is incompatible with and detrimental to normal functions inside these anatomical interconnectivities (e.g. anterograde or retrograde axonal transport processes), thus ultimately impeding the survival of interconnected nerve cells [16] and representing an integral component of and important step in the neurodegenerative process of SCA3. Since it allows several interpretations, the inverse correlation between the axonal pathology and CAG-repeat length unfortunately does not reveal unequivocal answers regarding an immediate detrimental or protective role of the intra-axonal inclusions. Longer CAG-repeats are commonly associated with more severe neurodegeneration [11, 20, 24, 27, 39, 45]. Assuming that intra-axonal aggregates are primarily detrimental to nerve cells, this inverse correlation may be due to a greater fibre loss in more severely affected SCA3 patients $[11,35]$. Since protein aggregation might also be primarily protective against soluble and harmful oligomers of the disease proteins [24, 46], the lower frequency of axonal aggregates in more severely diseased SCA3 patients, on the other hand, may reflect a less efficient protein handling in these patients.

In view of the current uncertainties regarding the pathogenic mechanisms of the neurodegenerative process of SCA3 and the possible significance of the newly described intra-axonal aggregates for the demise of affected and interconnected nerve cells, it appears worthwhile to perform additional studies aimed to test the hypothesis proposed above and to identify the exact pathophysiological causes and consequences of the intra-axonal aggregates in SCA3. 
Fig. 6 Anti-ataxin-3 and anti-p62 double immunofluorescence. Ataxin-3 immunopositive axonal aggregates in the pontocerebellar fibers $(\mathbf{a}-\mathbf{c})$ and in nerve cells of the caudal raphe nuclei of a representative SCA3 patient $(\mathbf{d}-\mathbf{f})$. The shuttle protein p62 (green) $(\mathbf{a}, \mathbf{d})$ is colocalized with ataxin-3 (red) $(\mathbf{b}, \mathbf{c}, \mathbf{e}, \mathbf{f})$ in these axonal aggregates (a-f Anti-p62 immunostaining with Alexa 488-green, anti-ataxin-3 immunostaining with Alexa 568—red, $100 \mu \mathrm{m}$ PEG sections)
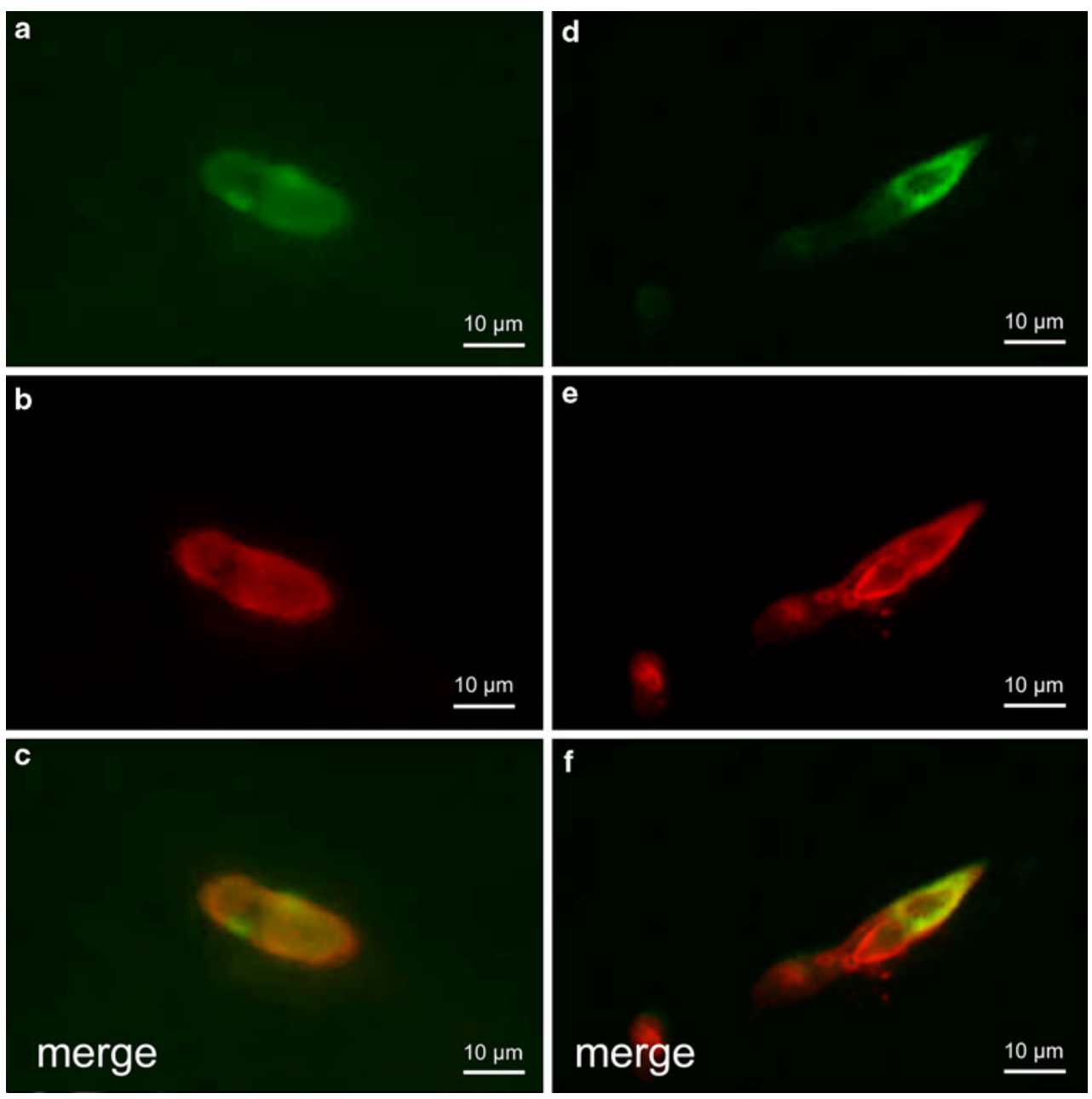

These studies should include (1) reconstruction of the spatial and temporal evolution of these axonal aggregates and their relationship to neurodegeneration, (2) investigation of axonal accumulation of cellular organelles and proteins involved in axonal transport mechanisms, (3) systematic investigation of animal models of SCA3 with different disease durations [52], and will contribute to a better understanding of the pathophysiological mechanisms of the neurodegenerative process of SCA3.

Acknowledgments This study was supported by grants from the Deutsche Forschungsgemeinschaft [RU 1215/1-2 to U.R., SCHU 1412/2-1 to C.S.]; the Deutsche Heredo-Ataxie Gesellschaft [DHAG to U.R.]; De Cock-Stichting Groningen [Project number 08-15 to W.d.D.]; the Prinses Beatrix Funds [PBF- WAR05-0129 to H.K. and E.B.]; the ADCA Vereniging Nederland [to U.R. and W.d.D.]; and the National Institutes of Health [NINDS RO1NS38712 to H.P.]. The skillful assistance of M. Babl, B. Meseck-Selchow, M. Bouzrou (processing of tissue sections and immunohistochemistry), J. Vinet (confocal microscopy), M. Hütten (secretary) and I. Szasz (graphics) is gratefully acknowledged. We would like to thank G. Auburger for the donation of the TDP-43 antibody.

Conflict of interest statement All authors have no actual or potential conflicts of interest to disclose, including financial, personal, or other relationships with other people or organizations, within 3 years after the submission of this work.

Open Access This article is distributed under the terms of the Creative Commons Attribution Noncommercial License which permits any noncommercial use, distribution, and reproduction in any medium, provided the original author(s) and source are credited.

\section{References}

1. Abele M, Bürk K, Andres F et al (1997) Autosomal dominant cerebellar ataxia type I: nerve conduction and evoked potential studies in families with SCA1, SCA2 and SCA3. Brain 120:2141-2148

2. Arai T, Nonaka T, Hasegawa M et al (2003) Neuronal and glial inclusions in frontotemporal dementia with or without motor neuron disease are immunopositive for p62. Neurosci Lett 342:41-44

3. Berke SJ, Chai Y, Marrs GL, Wen H, Paulson HL (2005) Defining the role of ubiquitin-interacting motifs in the polyglutamine disease protein, ataxin-3. J Biol Chem 280:32026-32034

4. Berod A, Hartman BK, Keller A, Joh TH, Pujol JF (1982) A new double labeling technique using tyrosine hydroxylase and dopamine-beta-hydroxylase immunohistochemistry: evidence for 
dopaminergic cells lying in the pons of the beef brain. Brain Res 240:235-243

5. Bichelmeier U, Schmidt T, Hübener J et al (2007) Nuclear localization of ataxin-3 is required for the manifestation of symptoms in SCA3: in vivo evidence. J Neurosci 27:7418-7428

6. Biernat J, Mandelkow EM, Schröter C et al (1992) The switch of tau protein to an Alzheimer-like state includes the phosphorylation of two serine-proline motifs upstream of the microtubule binding region. EMBO J 11:1593-1597

7. Bjorkoy G, Lamark T, Brech A et al (2005) p62/SQSTM1 forms protein aggregates degraded by autophagy and has a protective effect on huntingtin-induced cell death. J Cell Biol 171:602-614

8. Braak H, Rüb U, Del Tredici K (2003) Involvement of precerebellar nuclei in multiple system atrophy. Neuropathol Appl Neurobiol 29:60-76

9. Bürk K, Fetter M, Abele M et al (1999) Autosomal dominant cerebellar ataxia type I: oculomotor abnormalities in families with SCA1, SCA2 and SCA3. J Neurol 246:789-797

10. Ciechanover A (1998) The ubiquitin-proteasome pathway: on protein death and cell life. EMBO J 17:7151-7160

11. Cancel G, Abbas N, Stevanin G et al (1995) Marked phenotypic heterogeneity associated with expansion of a CAG repeat sequence at the spinocerebellar ataxia 3/Machado-Joseph disease locus. Am J Hum Genet 57:809-816

12. Ciani B, Layfield R, Cavey JR, Sheppard PW, Searle MS (2003) Structure of the ubiquitin-associated domain of p62 (SQSTM1) and implications for mutations that cause Paget's disease of bone. J Biol Chem 278:37409-37412

13. DiFiglia M, Sapp E, Chase CO et al (1997) Aggregation of huntingtin in neuronal intranuclear inclusions and dystrophic neurites in brain. Science 277:1990-1993

14. Gai WP, Power JHT, Blumbergs PC, Culvenor JG, Jensen PH (1999) Alpha-synuclein immunoisolation of glial inclusions from multiple system atrophy brain tissue reveals multiprotein components. J Neurochem 73:2093-2100

15. Goedert M, Jakes R, Crowther RA et al (1994) Epitope mapping of monoclonal antibodies to the paired helical filaments of Alzheimer's disease: identification of phosphorylation sites in tau protein. Biochem J 301:871-877

16. Gunawardena S (2005) Goldstein LSB (2005) Polyglutamine diseases and transport problems: deadly traffic jams on neuronal highways. Arch Neurol 62:46-51

17. Haan EA, Jennings IG, Cuello AC et al (1987) Identification of serotonergic neurons in human brain by monoclonal antibody binding to all three aromatic amino acid hydroxylases. Brain Res 426:19-27

18. Hayashi M, Kobayashi K, Furuta H (2003) Immunohistochemical study of neuronal intranuclear and cytoplasmic inclusions in Machado-Joseph disease. Psychiatry Clin Neurosci 57:205-213

19. Hoche F, Seidel K, Brunt ER et al (2008) Involvement of the auditory brainstem system in spinocerebellar ataxia type 2 (SCA2), type 3 (SCA3) and type 7 (SCA7). Neuropathol App1 Neurobiol 34:479-491

20. Kawaguchi $\mathrm{Y}$, Okamoto $\mathrm{T}$, Taniwaki $\mathrm{M}$ et al (1994) CAG expansions in a novel gene for Machado-Joseph disease at chromosome 14q32.1. Nat Genet 8:221-228

21. Klockgether T (2003) Ataxias. In: Goetz CG (ed) Textbook of clinical neurology, 2nd edn edn. Saunders, Philadelphia, pp 741-757

22. Kuusisto E, Kauppinen T, Alafuzoff I (2008) Use of p62/SQSTM antibodies for neuropathological diagnosis. Neuropathol Appl Neurobiol 34:169-180

23. Kuusisto E, Salminen A, Alafuzoff I (2003) Ubiquitin-binding protein p62 is present in neuronal and glial inclusions in human tauopathies and synucleinopathies. Neuroreport 12:2085-2090
24. Michalik A, van Broeckhoven C (2003) Pathogenesis of polyglutamine disorders: aggregation revisited. Hum Mol Genet 12:173-186

25. Orr HT, Zoghbi HY (2007) Trinucleotide repeat disorders. Annu Rev Neurosci 30:575-621

26. Paulson H (1999) Protein fate in neurodegenerative proteinopathies: Polyglutamine diseases join the (mis)fold. Am J Hum Genet 64:339-345

27. Paulson HL (2007) Dominantly inherited ataxias: lessons learned from Machado-Joseph disease/spinocerebellar ataxia type 3. Semin Neurol 27:133-142

28. Paulson H, Das S, Crino P et al (1997) Machado-Joseph disease gene product is a cytoplasmic protein widely expressed in brain. Ann Neurol 4:453-462

29. Paulson H, Perez M, Trottier Y et al (1997) Intranuclear inclusions of expanded polyglutamine protein in spinocerebellar ataxia type 3. Neuron 19:333-344

30. Perez M, Paulson H, Pendse S, Salonz S, Bonini N, Pittman R (1998) Recruitment and the role of nuclear localization in polyglutamine-mediated aggregation. J Cell Biol 143:1457-1470

31. Rüb U, Brunt ER, Deller T (2008) New insights into the pathoanatomy of spinocerebellar ataxia type 3 (Machado-Joseph disease). Curr Opin Neurol 21:111-116

32. Rüb U, Brunt E, Del Turco D et al (2003) Guidelines for the pathoanatomical examination of the lower brain stem in ingestive and swallowing disorders and its application to a dysphagic spinocerebellar ataxia type 3 patient. Neuropathol Appl Neurobiol 29:1-13

33. Rüb U, Brunt ER, Petrasch-Parwez E et al (2006) Degeneration of ingestion-related brainstem nuclei in spinocerebellar ataxia type 2, 3, 6 and 7. Neuropathol Appl Neurobiol 32:635-649

34. Rüb U, Brunt ER, de Vos RA et al (2004) Degeneration of the central vestibular system in spinocerebellar ataxia type 3 (SCA3) patients and its possible clinical significance. Neuropathol Appl Neurobiol 30:402-414

35. Rüb U, de Vos RA, Brunt ER et al (2006) Spinocerebellar ataxia type 3 (SCA3): thalamic neurodegeneration occurs independently from thalamic ataxin-3 immunopositive neuronal intranuclear inclusions. Brain Pathol 16:218-227

36. Rüb U, Gierga K, Brunt E et al (2005) Spinocerebellar ataxias type 2 and 3: degeneration of the precerebellar nuclei isolates the three phylogenetically defined regions of the cerebellum. J Neural Transm 112:1523-1545

37. Rüb U, Seidel K, Ozerden I et al (2007) Consistent affection of the central somatosensory system in spinocerebellar ataxia type 2 and type 3 and its significance for clinical symptoms and rehabilitative therapy. Brain Res Rev 53:235-249

38. Schmidt T, Landwehrmeyer GB, Schmitt I et al (1998) An isoform of ataxin-3 accumulates in the nucleus of neuronal cells in affected brain regions of SCA3 patients. Brain Pathol 8:669-679

39. Schöls L, Amoiridis G, Büttner T, Przuntek H, Epplen J, Riess O (1997) Autosomal dominant cerebellar ataxia: phenotypic differences in genetically defined subtypes. Ann Neurol 42:924-932

40. Schöls L, Bauer P, Schmidt T, Schulte T, Riess O (2004) Autosomal dominant cerebellar ataxias: clinical features, genetics and pathogenesis. Neurology 3:291-304

41. Seibenheimer ML, Babu JR, Geetha T, Wong HC, Krishna NR, Wooten MW (2004) Sequestosome 1/p62 is a polyubiquitin chain binding protein involved in ubiquitin proteasome degradation. Mol Cell Biol 24:8055-8068

42. Seidel K, Brunt ERP, de Vos RAI et al (2009) The p62 antibody reveals cytoplasmic protein aggregates in spinocerebellar ataxia type 6 (SCA6). Clin Neuropathol 28:344-349

43. Shaw G, Osborn M, Weber K (1981) An immunofluorescence microscopical study of the neurofilament triplet proteins, 
vimentin and glial fibrillary acidic protein within the adult rat brain. Eur J Cell Biol 26:68-82

44. Smithson KG, MacVicar BA, Hatton GI (1983) Polyethylene glycol embedding: a technique compatible with immunocytochemistry, enzyme histochemistry, histofluorescence and intracellular staining. J Neurosci Methods 7:27-41

45. Soong BW, Paulson HL (2007) Spinocerebellar ataxias: an update. Curr Opin Neurol 20:438-446

46. Takahashi T, Kikuchi S, Katada S, Nagai Y, Nishizawa M, Onodera O (2008) Soluble polyglutamine oligomers formed prior to inclusion body formation are cytotoxic. Hum Mol Genet $17: 345-356$

47. Tan CF, Yamada M, Toyoshima Y et al (2009) Selective occurence of TDP-43-immunoreactive inclusions in the lower motor neurons in Machado-Joseph disease. Acta Neuropathol 118:553-560

48. Trottier Y, Cancel G, An-Gourfinkel I et al (1998) Heterogeneous intranuclear localization and expression of ataxin-3. Neurobiol Dis 5:335-347
49. Trottier Y, Lutz Y, Stevanin G et al (1995) Polyglutamine expansion as a pathological epitope in Huntington's disease and four dominant cerebellar ataxias. Nature 378:403-406

50. Verschuuren-Bemelmans CC, Brunt ER, Burton M, Mensink RG, van der Meulen MA, Smit NH (1995) Refinement by linkage analysis in two large families of the candidate region of the third locus (SCA3) for autosomal dominant cerebellar ataxia type I. Hum Genet 96:691-694

51. Yamada M, Hayashi S, Tsuji S, Takahashi H (2001) Involvement of the cerebral cortex and autonomic ganglia in Machado Joseph disease. Acta Neuropathol 101:140-144

52. Yamada M, Sato T, Tsuji S, Takahashi H (2008) CAG repeat disorder models and human neuropathology: similarities and differences. Acta Neuropathol 115:71-86 